\title{
Variação prosódica das sentenças interrogativas totais no falar catarinense: um estudo experimental
}

\section{Juan Manuel Sosa}

Doutor em Linguística. Simon Fraser University, Canadá; Programa de Pós-Graduação em Linguística, Universidade Federal de Santa Catarina, Brasil.

sosa@sfu.ca

\section{Izabel Christine Seara}

Doutora em Linguística. Departamento de Língua e Literatura Vernáculas, Universidade Federal de Santa Catarina, Brasil.

izabels@linse.ufsc.br

Resumo: Neste estudo, analisamos a variação prosódica em enunciados interrogativos totais produzidos por falantes naturais de três cidades catarinenses: Florianópolis, Lages e Blumenau. Para isso, foram feitas comparações entre enunciados declarativos neutros e interrogativos totais, e os resultados foram ratificados através de testes perceptuais e estatísticos. Os dados constituem-se de um subconjunto de sentenças retiradas da base de dados do Projeto AMPERPOR, composto por seis informantes, dois de cada cidade, de ambos os sexos. Os resultados mostraram diferenças dialetais tanto na região nuclear (com maior evidência para o falante masculino de Lages) quanto na pré-nuclear (particularmente para os falantes blumenauenses).

Palavras-chave: Entoação; interrogativas totais; falar catarinense

\section{Vanessa Gonzaga Nunes}

Doutoranda em Linguística. Universidade Federal de Sergipe, Brasil.

vanessagnunes@yahoo.com.br
Abstract: In this paper we analyse the prosodic variation of yes/no questions as spoken by speakers of three cities in the state of Santa Catarina, Brazil: Florianopolis, Lages and Blumenau. We compared neutral declarative utterances and neutral yes/no questions and our results were corroborated by perception tests and statistical analyses. The data came from the AMPER-POR Project, with six informants of both genders, two from each city. Results show significant dialectal differences in the nuclear contours (especially for the male speakers from Lages), as well as in the prenuclear contours (particularly for both speakers from Blumenau).

Key-words: Intonation; Yes-no questions; Santa Catarina (Brazil) speech 



\section{Introdução}

Este estudo experimental trata da entoação de sentenças na modalidade interrogativa total no português brasileiro (doravante $\mathrm{PB}$ ), aquelas cujas respostas são sim ou não. Os dados investigados são referentes às cidades de Florianópolis (capital do estado de Santa Catarina), Lages e Blumenau e constituem a base de dados do Projeto AMPER-POR (Projeto Atlas Multimídia Prosódico do Espaço Dialetal Românico). ${ }^{1}$ O objetivo é observar se há diferenças na região pré-nuclear ou nuclear (ou no tom de fronteira) de sentenças interrogativas totais, considerando-se as produções de falantes oriundos dessas três cidades catarinenses. Para isso, faremos comparações dos contornos entonacionais de declarativas neutras e interrogativas totais.

As questões que queremos responder e as respectivas hipóteses levantadas são:

1.É possível observar diferenças entre dialetos de um mesmo estado em relação às interrogativas totais? A partir de uma primeira análise, realizada sobre ${ }^{1}$ http://pfonetica.web. ua.pt/AMPER-POR.htm as produções de falantes de Lages e Florianópolis, Nunes (2011) verificou que é no desenho do movimento interno às sílabas que parece haver diferenças entre os falares de Florianópolis e Lages, ou seja, no alinhamento do movimento de pitch dentro das sílabas tônicas. Assim, baseados nessas observações, nossa hipótese é a de que também encontraremos diferenças entre os falares de Blumenau, Lages e Florianópolis, e essas diferenças seriam perceptíveis para os falantes.

2.Se encontradas diferenças dialetais, elas estariam na região pré-nuclear ou na nuclear (ou no tom de fronteira)? A audição preliminar dos dados dessas cidades parece nos indicar diferenças localizadas não somente na região nuclear, mas também na região anterior ao núcleo entonacional. 
Assim, para responder a essas perguntas, apresentaremos na sequência uma revisão sobre como definimos interrogativas totais e quais as dificuldades para essa classificação. Em seguida, faremos uma apresentação da metodologia empregada para a coleta e a análise dos dados e citaremos as limitações encontradas no momento da coleta, da transcrição e do processamento dos dados. Descreveremos também os testes estatístico e perceptual realizados e, na sequência, exibiremos a análise dos dados. Por fim, responderemos às questões de pesquisa aqui colocadas.

Entendemos que, para os estudos prosódicos (e para os entonacionais em particular), é desejável tratar com dados de fala espontânea. Para o presente estudo, no entanto, consideramos necessário controlar as diferentes variáveis em jogo, a fim de verificar adequadamente a importância dos dados acústicos e de seus correlatos perceptivo e fonológico. Nesse sentido, situamonos na perspectiva de Xu (2010), em sua apologia aos experimentos controlados, baseados na chamada "fala de laboratório". Dessa maneira, este estudo enquadra-se na perspectiva de estudos entonacionais sobre dialetos como os que ocorrem na fala natural e sobre fatores relevantes e significativos das diversas variáveis identificadas e analisadas individualmente.

\section{As pesquisas sobre a entoação de interrogativas totais no PB}

Os estudos prosódicos sobre sentenças interrogativas evidenciam que nem sempre é fácil definir o que é uma interrogativa total. Sosa (1999), dentre outros, coloca que os enunciados interrogativos totais são perguntas às quais se podem responder com sim ou não. No entanto, dentro dessa modalidade, encontra-se um grande número de variantes, como as interrogativas de confirmação, de descrença ou 
dúvida, além ainda de interrogativas que não parecem se configurar como interrogativas, mas que são produzidas com a finalidade de se passar do desconhecido ao conhecido, como é o caso das interrogativas retóricas, tais como: Será verdade que Deus existe? Como não se esperam respostas de perguntas retóricas, elas não poderiam ser consideradas interrogativas. Sadock (1971, 1974 apud HAN, 2002), realizando testes com interrogativas retóricas, mostrou que elas são semanticamente equivalentes a uma afirmação.

No $\mathrm{PB}$, o que distingue uma interrogativa total de uma declarativa é a entoação, haja vista a não inversão sintática do sujeito e do verbo para a modalidade interrogativa, o que ocorre em outras línguas, como o inglês, por exemplo. No espanhol, um traço recorrente é o contorno final ascendente na interrogativa (SOSA, 1999). O contorno final da interrogativa é: (i) sempre maior do que qualquer outro ponto do enunciado nessa mesma modalidade e (ii) mais alto do que qualquer pico encontrado em declarativas. Dadas essas características sistemáticas no espanhol, o contorno final tornou-se um elemento relevante para distinção entre as modalidades declarativa e interrogativa. Foi observado ainda que a região pré-nuclear em um enunciado interrogativo é muito mais alta do que em um declarativo (SOSA, 1999). Vejamos tais características do espanhol na Figura 1, a seguir.

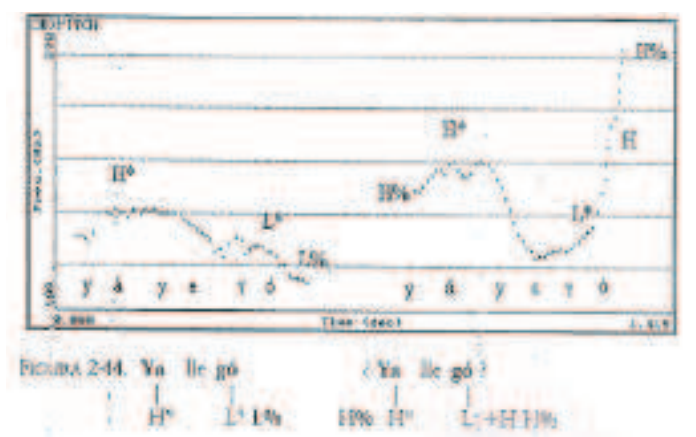

Fig. 1. Curva entonacional de um enunciado declarativo (à esquerda) e de um interrogativo (à direita) produzido por uma jovem de Lima (Peru) (SOSA, 1999, p. 153) 
Moraes e Stein (2006), para o português brasileiro, também alertam para as variedades possíveis dentro de um contorno melódico de uma sentença do tipo resposta $\mathrm{sim} /$ não. Os autores encontraram quatro padrões melódicos ligados a interrogativas totais e que podem ter representação fonológica distinta. São eles: (1) subida final típica de uma interrogativa total neutra, (2) subida interna ao sintagma relacionado a uma pergunta confirmativa, (3) subida tardia que caracteriza descrença ou dúvida e (4) subida dupla de uma interrogativa retórica.

Ainda, de acordo com Moraes e Stein (2006), os contornos melódicos do português sofrem a influência de fatores pragmáticos, que variam de acordo com a dependência do contexto conversacional. Fónagy (1993) registra que, diferentemente das emoções, as atitudes implícitas em uma sentença são motivadas pelo locutor e variam em um eixo de polaridade. Dessa forma, na escala de motivação, as interrogativas totais neutras tendem a ser menos motivadas por questões semânticopragmáticas ou atitudinais, como ocorre com as de surpresa ou descrença. Prévot (2004), apoiado em Borillo (1978) e Jayez (2002), afirma que a polaridade orienta a resposta esperada. As perguntas deslizam para funções outras que não apenas a informação. As interrogativas neutras, para esse autor, estariam na escala das questões verdadeiras ou sinceras. Do outro lado da escala, teríamos as questões que não pedem respostas de fato. Interrogativas totais neutras são, portanto, no nosso entendimento, sentenças que aceitam respostas $\mathrm{sim} /$ não, enunciadas por um falante que desconhece a resposta do emissor. Tal desconhecimento tende a minimizar as possíveis pistas de valor semântico-pragmático.

Moraes (2008) mostra que a curva melódica das interrogativas neutras é extremamente próxima daquelas que exprimem intenção de pedido, pois ambas apresentam movimentos semelhantes na região pré-nuclear e, 
para a região nuclear, movimento ascendente na sílaba tônica e descendente na pós-tônica. Então, como seria possível distinguir uma pergunta neutra de um pedido? Nesse caso, parece ser o movimento intrassilábico, ou seja, o alinhamento, o fator decisivo na distinção das modalidades. $\mathrm{O}$ alinhamento das interrogativas neutras ocorre no final da sílaba tônica, enquanto nas sentenças de pedido, o alinhamento se dá na porção inicial da sílaba tônica. A saída fonológica, sugerida por Moraes (2008), para interrogativas neutras é $/ \mathrm{L}+<\mathrm{H}^{*} \mathrm{~L} \% /$. Para Moraes

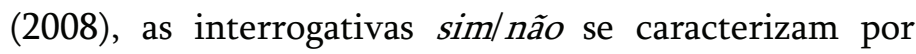
uma subida melódica na última sílaba acentuada caindo nas eventuais sílabas pós-tônicas. Esse é padrão para o português brasileiro (PB).

Reis, Antunes e Pinha (2011) analisaram sentenças declarativas e interrogativas totais, confrontando os dialetos mineiros de Belo Horizonte (capital de Minas Gerais) e de Mariana. Observaram em detalhes questões de alinhamento do pico de F0 intrassilábico na tentativa de encontrar diferenças entre sexos ou cidades. Consideraram três possibilidades de alinhamento: alinhamento em um ponto inicial, medial ou final da sílaba tônica, ou ainda alinhamento adiantado (na sílaba anterior à tônica) ou tardio (na sílaba seguinte à tônica). Seus resultados não foram conclusivos pela variação encontrada entre os sexos e entre as cidades, mas os dados demonstram que há uma proximidade no comportamento entonacional dos falantes dessas cidades, pois as curvas se mostram idênticas com respeito às características gerais dos movimentos melódicos, porém variam em relação ao alinhamento dos picos de F0.

Nunes (2011), analisando dados de falantes femininos e masculinos, com nível de escolaridade médio, das cidades de Florianópolis e Lages, conclui que os contornos nas tônicas em interrogativas totais apresentam variação em ambos os falares. As tônicas das 
oxítonas exibem, de modo geral, alinhamento medial, ou seja, temos um pico de $\mathrm{F} 0$ em algum ponto mais interno ao segmento e não em suas bordas inicial ou final. $\mathrm{O}$ florianopolitano apresenta essa distribuição de forma mais simétrica, pois o pico se mostra alinhado ao meio do núcleo silábico. Já o lageano expressa uma distribuição medial mais à direita. Nas paroxítonas, o florianopolitano traz o alinhamento do pico mais central, enquanto o lageano realiza o movimento mais à direita. Nas proparoxítonas, ambos os informantes apresentam alinhamentos mais à direita. Na Figura 2, podem ser observados exemplos desses movimentos na sílaba tônica da região nuclear de falantes de Florianópolis e de Lages.

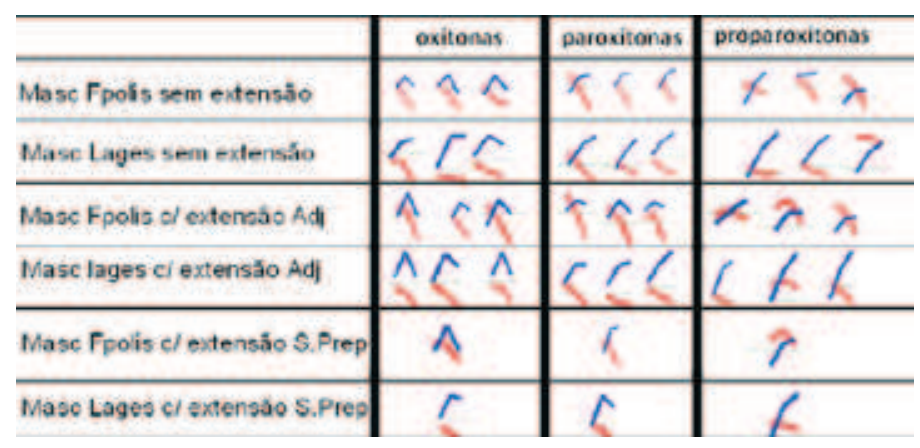

Fig. 2. Em detalhe, apenas as sílabas tônicas do núcleo entonacional. Em vermelho, as declarativas e, em azul, as interrogativas (NUNES, 2011, p.112).

Rebollo-Couto e Seara (2011), comparando interrogativas totais dos dialetos fluminense e florianopolitano, observaram haver diferenças de implementação com relação aos núcleos, parecendo que, nas interrogativas totais do falar fluminense, haveria uma preferência pelo alinhamento antecipado (mais à esquerda da sílaba acentuada), enquanto, no florianopolitano, haveria um alinhamento medial ou mais à direita. Esse contorno circunflexo alinhado mais à direita para dados de florianopolitanos também foi observado por Silva e Cunha (2011). 
Toledo e Gurlekian (2009), pesquisando produções de sentenças interrogativas totais de informantes femininos, falantes do espanhol de Buenos Aires, com escolaridade média, encontraram outro movimento distinto da subida ascendente na região de núcleo que caracteriza a pergunta no espanhol de Buenos Aires, é o tom circunflexo, observado em palavras paroxítonas e proparoxítonas. Em sentenças interrogativas finalizadas por palavras oxítonas, o contorno exibe um efeito de truncamento em seu movimento final ascendente. Isso parece mostrar que o contorno final das interrogativas no espanhol de Buenos Aires é fonologicamente ascendente-descendente, como acontece no PB, mas, também por conta da brevidade da sílaba tônica final das oxítonas, o movimento em circunflexo não é plenamente realizado. Silva (2011) também observou esses dois padrões em enunciados interrogativos espontâneos em 24 capitais brasileiras (de norte a sul do país).

Seara, Figueiredo-Silva e Berri (2011), investigando o sintagma nominal sujeito de sentenças que compõem o corpus do Projeto AMPER, constataram que, para falantes florianopolitanos, não foram observadas diferenças entre sentenças declarativas e interrogativas totais nessa região pré-nuclear.

\section{O recorte metodológico}

Neste estudo, estamos analisando dados entonacionais relativos à modalidade interrogativa total, a partir de dados de falantes nativos de três cidades catarinenses: Florianópolis, Lages e Blumenau. Este estudo integra o projeto de pesquisa: $O$ detalhe fonético: análise acústica exploratória de segmentos de fala, aprovado pelo Comitê de Ética em Pesquisa com Seres Humanos (CEPSH) da Pró-Reitoria em Pesquisa e Extensão da Universidade Federal de Santa Catarina (Processo ${ }^{\circ}$. 2057), e todos os 
informantes envolvidos nas gravações de dados assinaram o Termo de Consentimento Livre e Esclarecido.

Sobre os tipos de interrogativas do $\mathrm{PB}$, as características descritas por Moraes e Stein (2006) parecem ser sistemáticas para todos os dialetos. Isso nos permite ter critérios para categorizar subgrupos de interrogativas totais, haja vista a dificuldade de obtenção de interrogativas neutras $\mathrm{sim} /$ não nos dados coletados para o Projeto AMPER. Por conta dessa dificuldade e da percepção de que temos, além de interrogativas $\operatorname{sim} /$ não, interrogativas de confirmação, de descrença ou dúvida ou mesmo retóricas, selecionamos de oitiva aquelas que mais se adequavam ao que consideramos interrogativas $\mathrm{sim} /$ não. Nesse caso, a entoação corresponde a uma pergunta para a qual certamente não sabemos a resposta.

Nossos dados são de falantes florianopolitanos, blumenauenses e lageanos, nascidos e criados nas cidades catarinenses de Florianópolis, Blumenau e Lages, respectivamente. No mapa, exibido na Figura 3, podemos ver a disposição geográfica dessas cidades no estado de Santa Catarina.

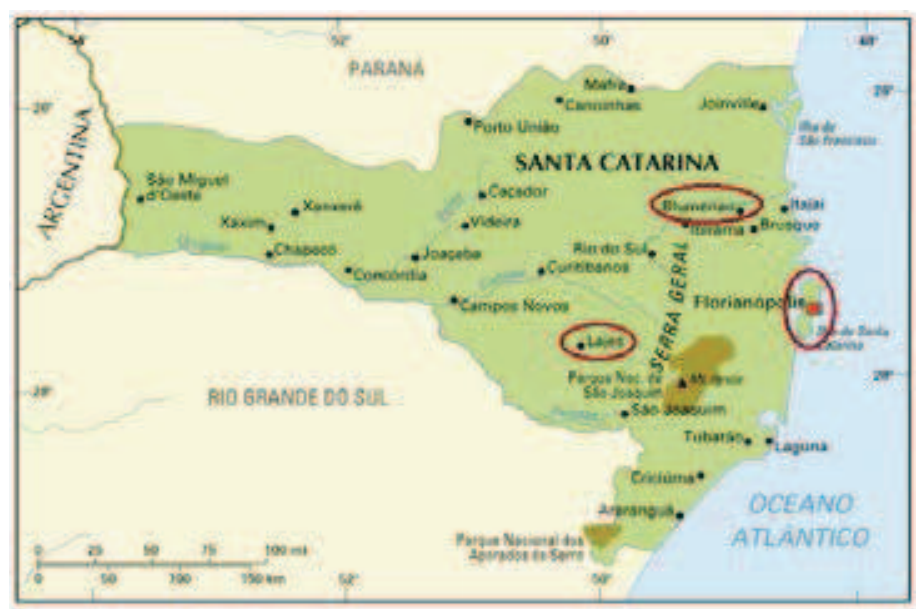

Fig. 3. Florianópolis, região centro-leste de Santa Catarina; Lages, no Planalto Serrano; e Blumenau, mais ao norte, no Vale de Itajaí, conforme a representação no mapa do estado de Santa Catarina. 
Este estudo baseia-se em dados do Projeto AMPER, que conta com um corpus fixo, cujas sentenças declarativas neutras e interrogativas totais são obtidas por estímulos visuais e podem ser comparadas a outras semelhantes, ou seja, com o mesmo número de sílabas e posição de acento. O corpus do português brasileiro é uma adaptação do corpus utilizado para o português europeu e obedece a critérios linguísticos, como número de sílabas (de 10 a 14), palavras com as três possibilidades acentuais do PB (proparoxítona, paroxítona e oxítona) e sentenças formadas por sujeito + verbo + complemento (com ou sem extensões).

Os dados aqui analisados compreendem seis sujeitos, dois de cada localidade, sendo um masculino e um feminino, com idades variando de 30 a 45 anos e com 12 anos de escolaridade (nível médio). Todos eram nascidos nas cidades da coleta e seus pais também eram nascidos nessas mesmas cidades. Foram gravadas 66 sentenças, repetidas 3 vezes, perfazendo um total de 1.188 sentenças ( 66 sentenças $\times 3$ repetições $\times 3$ localidades $\times 2$ sexos). No entanto, não foi possível contar com todas as sentenças coletadas, devido a limitações que os dados do Projeto AMPER apresentaram, algumas já salientadas em Reis, Antunes e Pinha (2011). Vejamos:

a) houve leituras equivocadas das imagens e, algumas vezes, os sujeitos esqueciam a que palavra se referiam algumas dessas figuras, levando a uma produção não natural;

b) houve estranhamento das situações apresentadas pelas figuras, levando a uma leitura, por exemplo, de interrogativa de confirmação;

c) algumas das sentenças foram produzidas com mais de um sintagma entonacional; outras apresentavam ênfase em um dos elementos da 
${ }^{2}$ Essas etiquetagens foram realizadas com o auxílio do programa de análise de fala Praat, desenvolvido por Paul Boersma e David Weenink, que pode ser obtido livremente no endereço eletrônico: http://www.praat.org.

${ }^{3}$ Agradecemos à doutoranda Eva Christina Orzechowski Dias pelo auxílio nas rodadas estatísticas.

${ }^{4}$ SPSS Statistic 17.0. Polar Engineering and Consulting, copyright 1993-2007. sentença ou ainda exibiam pausas de hesitação ou disfluências;

d) em algumas das sentenças produzidas, houve uma focalização aleatória, não justificada e nem controlada (especialmente para as declarativas).

Dessa forma, levando-se em conta que os dados podem ser falseados quando as frases analisadas não puderem ser comparadas com respeito ao seu sentido e à sua intenção, todas as sentenças foram ouvidas, e aquelas que não apresentavam características de sentenças neutras foram descartadas dessa primeira análise.

Assim, avaliamos um total de 382 sentenças declarativas neutras e 382 interrogativas $\operatorname{sim} /$ não (totais). Os resultados apresentados a seguir se referem às análises dessas sentenças.

Para as comparações das sentenças, utilizamos as rotinas de análise estabelecidas pelo Projeto AMPER, que considera a segmentação das vogais das sentenças em análise ${ }^{2}$, obtendo-se cinco valores para cada uma delas: duração, intensidade global, frequência fundamental (F0) inicial, medial e final. Com esses parâmetros, são gerados arquivos de dados, tonais e gráficos com sobreposição das curvas das modalidades declarativa e interrogativa a partir da média de três repetições da mesma sentença, conforme a Figura 4, na próxima seção. No presente estudo, baseamo-nos apenas nos valores de F0 medial.

Para o tratamento estatístico ${ }^{3}$, utilizamos o Programa SPSS 4 . O objetivo do teste estatístico é verificar se há diferenças significativas nos valores de F0 entre as modalidades declarativa e interrogativa. Como variável dependente foi considerada a frequência fundamental (F0) e como variáveis independentes, a posição da vogal na região pré-nuclear (tônica e pós-tônica), a modalidade da 
sentença (declarativa e interrogativa) e o sexo (masculino e feminino).

Como o conjunto de dados para cada grupo de variáveis era pequeno, correspondendo a vinte dados em cada grupo, optou-se por utilizar o teste não paramétrico Mann-Whitney $U$, que compara dois grupos independentes (MARTINS, 2011). A partir do valor de $p$ (probabilidade de significância), observou-se se as diferenças eram ou não significativas: valores abaixo de 0,05 foram considerados significativos, e valores acima de 0,05 foram considerados não significativos, conforme convencionado em pesquisas sociais (BARBETTA, 2011).

Realizamos ainda um teste de percepção a partir de 116 estímulos nos quais o sujeito ouve o início de uma sentença em fala natural associado à produção de uma interrogativa total ou declarativa neutra. O ouvinte deveria indicar se ele considerava o estímulo como sendo de uma sentença interrogativa ou de uma declarativa. O objetivo do teste é verificar se o ouvinte consegue identificar a modalidade da sentença apenas com a informação contida no SN-sujeito. Esse teste foi montado com o auxílio do software de análise de fala Praat, e os resultados foram coletados automaticamente pelo mesmo software.

\section{A análise entonacional dos dados coletados}

Considerando-se apenas as produções que representaram adequadamente a entoação de uma interrogativa total neutra, tentamos observar o que foi mais recorrente.

Nos contornos finais interrogativos, ocorre sistematicamente um tom ascendente-descendente (o tom circunflexo - Figura 4.a). Nos falares aqui tratados, e aparentemente para todo o português brasileiro, a 
interrogativa total tem a notação $\mathrm{L}+\mathrm{H}^{*} \mathrm{~L} \%$, conforme a Figura 4, com variantes implementacionais.

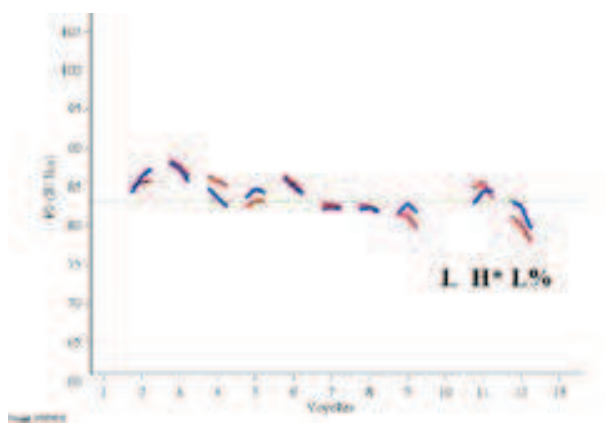

(a)

${ }^{5}$ Esse apagamento de vogais ocorre em sílabas postônicas, em particular se a consoante é não-vozeada como em Renato [Xe nat], pássaro ['pasru], pateta [pa'tEt].

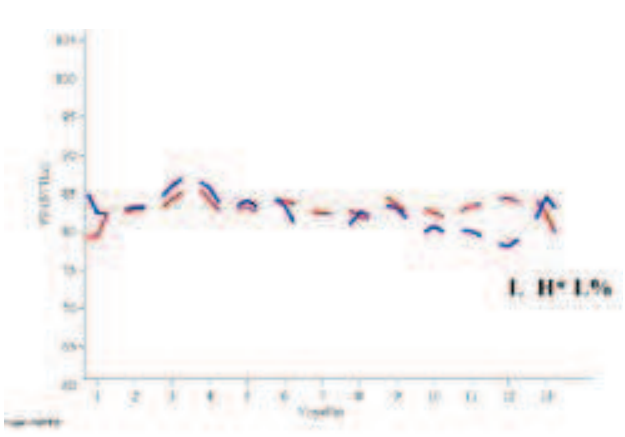

(b)

Fig. 4. Modalidades declarativa (em vermelho) e interrogativa total (em azul) das sentenças $O$ Renato gosta do pássaro bêbado e $O$ Renato gosta do pássaro nadador do informante florianopolitano.

Ocorreu, com muita frequência, nas sentenças finalizadas por palavras oxítonas e nos casos de apagamento ou ensurdecimento (ou elisão) de vogais finais ${ }^{5}$, o fenômeno de truncamento, que se caracteriza pela produção incompleta do contorno circunflexo (Figura 4.b). Ou seja, não se nota a parte final do movimento circunflexo - o movimento de descida, análogo ao que ocorre no espanhol de Buenos Aires, segundo Toledo e Gurlekian (2009). Esse fenômeno tem sido observado por pesquisadores, incluindo Quilis 
(1988), mais anteriormente, e Silva (2011) e Dias e Alves (2013), mais recentemente, quando sugerem que as sentenças finalizadas por oxítonas apresentam um padrão sistemático de movimento ascendente, contrariamente às paroxítonas.

Para a observação do comportamento entonacional das sentenças produzidas por cada informante em separado, iniciamos nossas análises com o falante masculino de Lages, por conta da variação que apresenta.

Os contornos de pitch das sentenças interrogativas do informante lageano, mostrados na Figura 5, evidenciam a variação encontrada. Vejamos: na Figura 5.a, temos o contorno ascendente-descendente da sentença interrogativa $O$ Renato nadador gosta do pássaro?, a mais recorrente nos dados analisados, independentemente da posição do acento na palavra que ocorre no núcleo da sentença (notação $\mathrm{L}+\mathrm{H}^{*} \mathrm{~L} \%$ ). Na Figura 5.b, temos um exemplo de truncamento do movimento descendente, na interrogativa $O$ pássaro pateta gosta do bisavô? que finaliza antes do movimento de descida ser completado (notação $\mathrm{L}+\mathrm{H}^{*} \mathrm{~L} \%$ ). E, na Figura 5.c, observa-se apenas um movimento ascendente (notação $\mathrm{L}+\mathrm{H} * \mathrm{H} \%$ ), já salientado por Silva (2011) e Dias e Alves (2013). As diferenças observadas no núcleo das sentenças interrogativas, apresentadas nas Figuras 5.b e 5.c, entre o valor de pitch mais baixo e o seu ponto final mais alto são de, aproximadamente, uma oitava (o dobro da frequência mais baixa). Essas diferenças são notadas tanto para o núcleo com truncamento quanto para o núcleo com apenas o movimento ascendente ${ }^{6}$.

De modo geral, para o falante masculino de Lages, na região nuclear, os finais parecem descendentes, porém, algumas produções apresentaram truncamento até mesmo em paroxítonas, cuja última vogal átona era apagada. Assim, esse truncamento do movimento descendente ocorre, como já salientamos, por falta de material silábico suficiente para implementar essa

\footnotetext{
${ }^{6}$ Esse movimento ascendente pragmaticamente parece remeter a uma pergunta que espera uma resposta positiva, diferentemente dos dois outros contornos, em que se esperaria tanto uma resposta positiva quanto negativa. Testes perceptuais ainda precisam ser realizados para comprovação dessa constatação.
} 
descida do tom. No entanto, esse contorno descendente deve estar presente subjacentemente, em especial, como já foi destacado, nas oxítonas finais, daí ter a mesma notação prosódica do movimento padrão circunflexo $\left(\mathrm{L}+\mathrm{H}^{*} \mathrm{~L} \%\right)$. A verificação de que a maioria das sentenças interrogativas totais apresenta curva ascendentedescendente na região de núcleo, mesmo para aquelas finalizadas por oxítonas ou por apagamento de vogais finais, parece ser um argumento a favor do truncamento do movimento de descida.

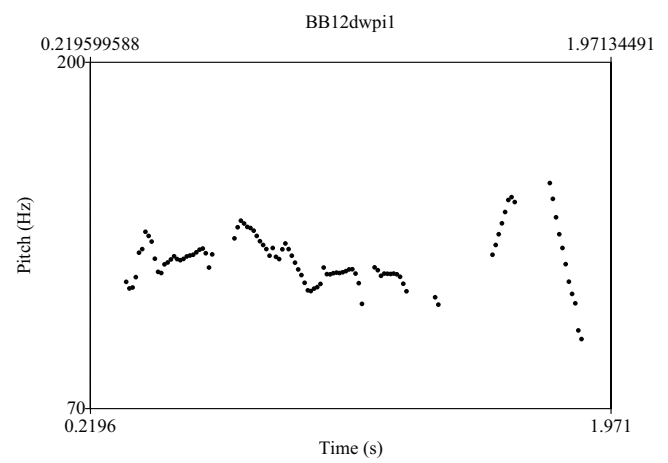

(a) $\mathrm{L} \mathrm{H}^{*} \mathrm{~L} \%$

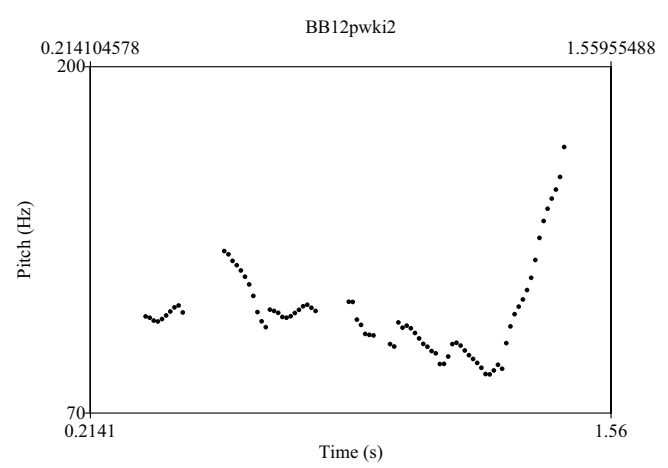

(b) $\mathrm{L} \mathrm{H}^{*} \mathrm{~L} \%$ 


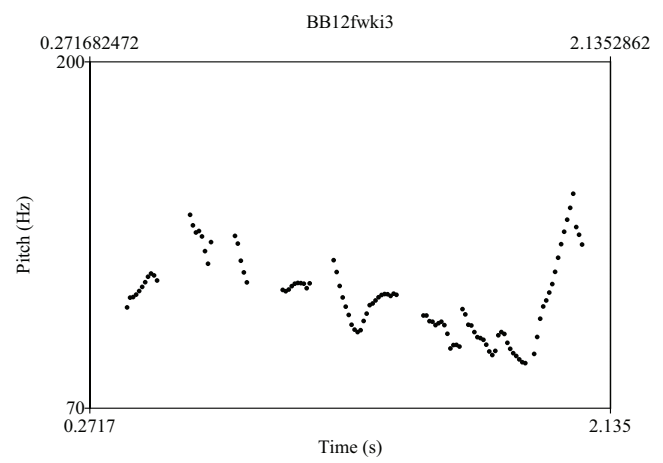

(c) $\mathrm{L} \mathrm{H}^{*} \mathrm{H} \%$

Fig. 5. Contorno de pitch das sentenças interrogativas na região nuclear, produzidas pelo falante masculino de Lages: (a) O Renato nadador gosta do pássaro? apresentando movimento ascendentedescendente; (b) O pássaro pateta gosta do bisavô?, exibindo um truncamento no movimento ascendente-descendente; (c) O pássaro gosta do bisavô? mostrando um movimento apenas ascendente.

Agora, comparando os contornos de declarativa e interrogativa, ainda nos dados do falante masculino de Lages, percebemos que o pré-núcleo é virtualmente idêntico nas interrogativas e declarativas (Figura 6). E a entoação global apresenta-se plana, sem subidas e/ou descidas muito evidentes no corpo do enunciado.

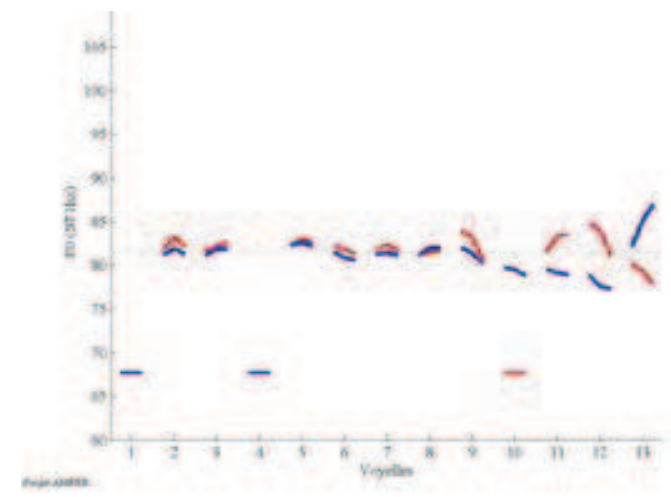

Fig. 6. Modalidades declarativa (em vermelho) e interrogativa total (em azul) da sentença $O$ Renato nadador gosta do pássaro do informante masculino de Lages. 
A falante feminina de Lages tem contornos interrogativos finais parecendo mais neutros e, quando comparada à falante florianopolitana, há contraste pela grande variação de tom encontrada nas produções da florianopolitana. Na região pré-nuclear, também não existem muitos movimentos se comparamos as produções interrogativas com as declarativas da falante lageana.

Os dados do falante masculino florianopolitano não parecem apresentar diferenças importantes no prénúcleo entre as modalidades interrogativas e declarativas. $\mathrm{E}$ a região nuclear comporta-se conforme o esperado, com um movimento circunflexo.

No entanto, a falante feminina de Florianópolis apresenta um grande campo entonacional na região nuclear e exibe ao menos um contorno ascendente, conforme se percebe na Figura 7. No caso dos contornos finais ascendente-descendente dessa falante, pensamos que poderia tratar-se de foco estreito no núcleo. Três frases desta falante apresentam esse amplo campo entonacional, porém o resultado não parece coerente com o desenho entonativo para que se possam apresentar conclusões mais contundentes. Em muitas situações, percebe-se certa aleatoriedade no foco e na intenção da falante em cada interrogativa, como no caso do contorno final apresentado na Figura 7, que também não segue o padrão típico ascendente-descendente da interrogativa total.

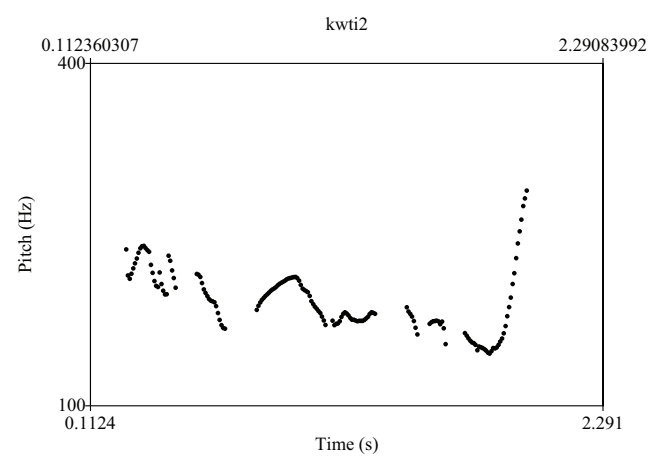

Fig. 7. Contorno de pitch da sentença interrogativa O bisavô gosta do Renato?, produzida pela falante feminina de Florianópolis. 
Passemos agora à cidade de Blumenau. As interrogativas dos falantes de Blumenau apresentam o núcleo esperado para o padrão do $\mathrm{PB}$. No entanto, exibem a primeira sílaba tônica da região pré-nuclear das interrogativas mais alta se comparada às declarativas, conforme Figura 8 na próxima seção. Esse contorno já é visto em espanhol (conforme SOSA, 1999).

\section{A análise dos valores de Fo}

Para verificação da relevância estatística das diferenças observadas na região pré-nuclear para a cidade de Blumenau, foram investigados os valores de F0 das posições tônicas e pós-tônicas dessa região em sentenças declarativas e interrogativas, que eram constituídas das palavras Renato ou pássaro. A Tabela 1 apresenta os resultados desse teste estatístico.

\begin{tabular}{|c|c|c|c|c|c|c|}
\hline \multirow[b]{2}{*}{ Posição } & \multirow[b]{2}{*}{ Sujeito } & \multicolumn{2}{|c|}{ Declarativa } & \multicolumn{2}{|c|}{ Interrogativa } & \multirow{2}{*}{$\begin{array}{c}\text { Teste }^{7} \\
\text { (pós-tônica } \times \text { tônica) }\end{array}$} \\
\hline & & Média (DP) & N. dados & Média (DP) & N. dados & \\
\hline \multirow[t]{2}{*}{ Tônica } & Masculino & $125(3)$ & 20 & $151(10)$ & 20 & $Z=-5,42, p<, 001$ \\
\hline & Feminino & $204(11)$ & 20 & $283(47)$ & 20 & $Z=-3,89, p<, 001$ \\
\hline \multirow[t]{2}{*}{ Pós-tônica } & Masculino & $147(6)$ & 20 & $138(6)$ & 20 & $Z=-4,64, p<, 001$ \\
\hline & Feminino & $253(29)$ & 20 & $319(37)$ & 20 & $Z=-4,77, p<, 001$ \\
\hline
\end{tabular}

Tabela 1. Valores médios e desvios padrões da frequência fundamental (F0), em Hz, encontrados nas posições tônica e pós-tônica da região pré-nuclear das modalidades declarativa e interrogativa, referentes aos grupos masculino e feminino da cidade de Blumenau, e comparação entre essas modalidades.

Ao comparar os valores de F0 das modalidades declarativa e interrogativa, com relação às posições tônicas e pós-tônicas da região pré-nuclear, o Teste de Mann-Whitney $U$ mostrou que há diferenças significativas. Desse modo, para a posição tônica, a modalidade interrogativa apresentou valores de F0 significativamente mais altos do que a declarativa, tanto 
para o grupo masculino quanto para o feminino. Já, para a posição pós-tônica, a modalidade interrogativa apresentou valores de F0 significativamente mais baixos do que a modalidade declarativa para o sexo masculino, e mais altos para o sexo feminino.

Uma conclusão preliminar seria a de que, na comparação interdialetal, o contorno entonacional dos falantes de Blumenau se distingue dos demais nas diferenças que apresentam em seus pré-núcleos interrogativos, exibindo maior altura e configuração distinta, comparativamente aos declarativos, conforme pode ser visto na Figura 8. Isso parece não ocorrer com os lageanos e os florianopolitanos.

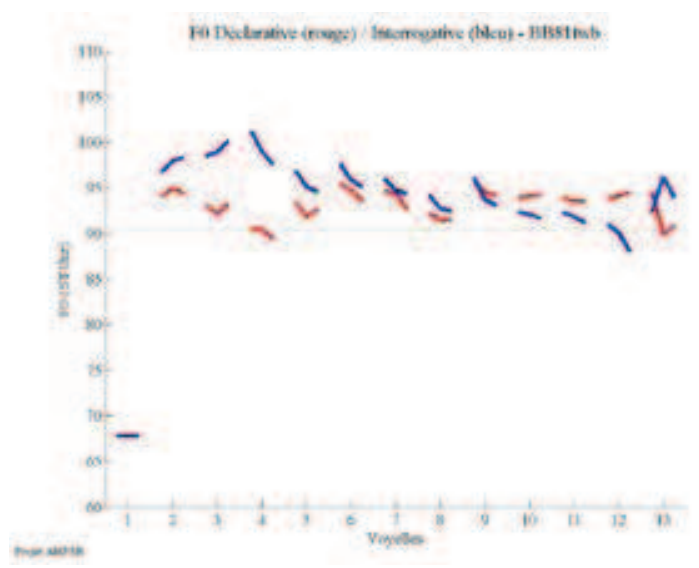

Fig. 8. Modalidade interrogativa total: produção blumenauense de uma sentença interrogativa total (em azul) e de uma declarativa neutra (em vermelho) da sentença $O$ Renato gosta do pássaro nadador.

\section{Testes de percepção}

Em função das diferenças estatísticas verificadas, foram montados testes com estímulos que verificavam a percepção dos ouvintes quanto às diferenças na região pré-nuclear das sentenças. Esses testes de percepção consistiam em escutar somente o início de uma sentença 
em fala natural, o seu SN-sujeito, que estaria associado a uma sentença que foi produzida como interrogativa total ou como declarativa neutra. Como resposta, o ouvinte deveria indicar se ele considerava esse início como sendo de uma sentença interrogativa ou de uma declarativa. O objetivo do teste foi verificar se o ouvinte consegue identificar a modalidade da sentença apenas com a informação contida no $\mathrm{SN}$-sujeito - na região pré-nuclear. Utilizamos um total de 116 estímulos, 58 declarativos e 58 interrogativos, com $\mathrm{SN}$-sujeitos provenientes de sentenças dos seis informantes aqui pesquisados.

Os testes foram realizados com oito ouvintes e os resultados se mostraram muito mais consistentes quando relacionados aos falantes blumenauenses do que em relação aos florianopolitanos e lageanos. Baseamos a consistência dos dados na consideração do número de acertos dos ouvintes com respeito à sentença à qual pertencia o $\mathrm{SN}$ sujeito. Nas produções dos blumenauenses, o número de acertos foi superior a $50 \%$ e, dentre eles, três dos ouvintes apresentaram percentual de acerto superior a $65 \%$. Isso quer dizer que, em $65 \%$ dos estímulos, apenas o SNsujeito, localizado na região pré-nuclear, era suficiente para a percepção de uma interrogativa ou declarativa. Para os lageanos e florianopolitanos, as respostas ficaram sempre muito próximas de $50 \%$, indicando a aleatoriedade dos dados.

Passemos então às respostas aos questionamentos inicias e às nossas conclusões ainda preliminares, haja vista a necessidade, em alguns casos, de testes de percepção ou estatísticos para melhor comprovação de que todas as diferenças observadas são perceptíveis para os falantes.

\section{Conclusões}

$\mathrm{Na}$ presente investigação, comparamos os contornos interrogativos e declarativos de falantes de 
três cidades catarinenses, e concluímos que efetivamente existem diferenças entonacionais que são sistemáticas e que definem comportamentos entonacionais distintos entre falantes dessas diferentes regiões catarinenses. $\mathrm{O}$ contorno entonacional das interrogativas é diferente em pontos específicos nas variedades aqui tratadas Florianópolis, Lages e Blumenau.

Respondendo às nossas perguntas de pesquisa, verificamos diferenças entre os três dialetos. Essas diferenças referem-se à grande variação de contornos na região nuclear, assinalada para o falante lageano, que mostrou contornos ascendente-descendente (o tom circunflexo), truncamentos e contornos apenas ascendentes. Assim, esses resultados vêm se juntar à observação de uma variação já apontada por Nunes (2011) para os falantes lageanos em relação aos florianopolitanos (movimento intrassilábico), ratificando essas diferenças dialetais entre lageanos e florianopolitanos. Em um próximo estudo, verificaremos a percepção dos falantes quanto a essas diferenças na região nuclear com testes de percepção sistematizados como aqueles realizados para a região pré-nuclear.

Foram também encontradas diferenças na região pré-nuclear nos dados dos falantes blumenauenses que não foram constatadas nos dados dos demais dialetos aqui investigados. Para os blumenauenses, as interrogativas $\mathrm{sim} /$ não apresentam diferença de contorno entonacional na região pré-nuclear, que é significativamente mais alta do que nas declarativas. Tal característica constitui-se em uma pista usada pelos falantes para diferenciar as duas modalidades. Esses resultados foram corroborados pelo teste estatístico e pelo teste de percepção. 


\section{Referências}

BARBETTA, Pedro A. Estatística Aplicada às Ciências Sociais. 5. ed. Florianópolis: Editora da UFSC, 2011.

BORILLO, Andrée. Structure et valeur énonciative de l'interrogation totale en français. Tese (Thèse d'Etat). Université d'Aix-en- Provence, 1978.

DIAS, Eva C. O.; ALVES, Mariane A. Análise de Produção de Sentenças Interrogativas Totais em Aprendizes Brasileiros de Espanhol como Língua Estrangeira. Journal of Speech Sciences, 2013, v. 2, p. 43-63, 2013.

FÓNAGY, Ivan. As funções modais da entoação. Cadernos de Estudos Linguísticos. Campinas, 1993, p. 25-65, jul/dez, 1993.

HAN, Chung-hye. Interpreting interrogatives as rhetorical questions. Lingua, [S.1.], n.112, p. 201-229, 2002.

JAYEZ, Jacques. Modal attachment for discourse markers. In C. Beyssade et al. (Eds.) Questions Empiriques et Formalisation en Syntaxe et Sémantique, Proceedings of CSSP 2001, Paris: Presses Universitaires de Paris-Sorbonne, p. 309327, 2002.

MARTINS, Carla. Manual de análise de dados quantitativos com recurso ao IBM SPSS. Braga: Psiquilibríos Edições, 20011.

MORAES, João A.; STEIN, Cirineu C. Attitudinal patterns in Brazilian Portuguese intonation: analysis and synthesis. International Conference on Speech Prosody, 3, 2006,

Dresden. Proceedings..., Dresden: [s.n.], 2006.p. 137-141.

MORAES, João A. The Pitch Accents in Brazilian Portuguese: analysis by synthesis. Speech Prosody, 4, 2008, Campinas. Proceedings..., Campinas, 2008. p. 389-397.

NUNES, Vanessa G. Análises entonacionais de sentenças declarativas e interrogativas totais nos falares florianopolitano e lageano. Dissertação (Mestrado em Linguística) Universidade Federal de Santa Catarina, 2011. 
PRÉVOT, Laurent. Structures sémantiques et pragmatiques pour la modélisation de la cohérence dans des dialogues finalisés. Tese (Doutorado). Université Paul Sabatier, Toulouse III, 2004.

QUILIS, Antonio. Estudio comparativo entre la entonación portuguesa (de Brasil) y la española. Revista de Filologia Española, [S.1.], n.68, p. 33-65, 1988.

REIS, Cesar; ANTUNES, Leandra B.; PINHA, Vanessa. C. de J. Prosódia de declarativas e interrogativas totais no falar marianense e belorizontino no âmbito do Projeto AMPER. Colóquio Brasileiro de Prosódia da Fala, 3, 2011, Belo Horizonte. Anais... Belo Horizonte: [s.n.], 2011. p. 1-6.

SADOCK, Jerry M. Queclaratives. Regional Meeting of the Chicago Linguistic Society, 7, 1971, Papers from the Seventh Regional Meeting of the Chicago Linguistic Society, Chicago: Chicago Linguistics Society, 1971. p. 223-232.

SADOCK, Jerry M. Towards a linguistic theory of speech acts. New York: Academic Press, 1974.

SEARA, Izabel C.; REBOLLO-COUTO, Letícia. Entoação de frases declarativas e interrogativas no falar fluminense e catarinense. Congreso Internacional de la ALFAL, 16, 2011, Alcalá de Henares (Espanha). Actas... Alcalá de Henares (Espanha): Universidad de Alcalá, 2011. p. 01-07.

SEARA, Izabel C.; FIGUEIREDO-SILVA, Maria Cristina; BERRI, André R. A entoação do SN-Sujeito no PB falado em Florianópolis: sentenças declarativas e interrogativas totais. Revista Internacional de Linguística Iberoamericana, Frankfurt (Alemanha), v. IX, p. 157-168, 2011.

SILVA, Joelma C. B. A Prosódia regional em enunciados interrogativos espontâneos do português do Brasil. Revista Gatilho, (ano VII, v.13, set., p.1-13, 2011. Disponível em < http://www.ufff.br/revistagatilho/> Acesso em: 23 nov.2012.

SILVA, Joelma C. B.; CUNHA, C. S. Caracterização prosódica dos falares brasileiros: a questão total em Recife, Rio de Janeiro e Florianópolis. Antares, Letras e Humanidades, [S.1.], v. 3, n.6, p. 282-294, jul./dez. 2011. 
SOSA, Juan M. La entonación Del español: su estructura

fónica, variabilidad y dialectologia. Catedra: Madrid, 1999.

$264 \mathrm{p}$.

TOLEDO, Guillermo A.; GURLEKIAN, Jorge. Amper-

Argentina: tonemas en oraciones interrogativas absolutas.

Estudios de Fonética Experimental, Barcelona, n.18, p. 401415, 2009.

XU, Yi. In defense of lab speech. Journal of Phonetics, [S.1.], 38, p. 329-536, 2010.

[Recebido em 16 de junho de 2013

e aceito para publicação em 16 de novembro de 2013] 